(2) Open Access Full Text Article

\title{
Dietary arginine silicate inositol complex increased bone healing: histologic and histomorphometric
} study

\author{
Ferhan Yaman' \\ Izzet Acikan' \\ Serkan Dundar ${ }^{2}$ \\ Sercan Simsek ${ }^{3}$ \\ Mehmet Gul ${ }^{4}$ \\ İbrahim Hanifi Ozercan ${ }^{3}$ \\ James Komorowski ${ }^{5}$ \\ Kazim Sahin 6 \\ 'Department of Oral-Maxillofacial \\ Surgery, Faculty of Dentistry, Dicle \\ University, Diyarbakir, Turkey; \\ ${ }^{2}$ Department of Periodontology, \\ Faculty of Dentistry, Firat University, \\ Elazig, Turkey; ${ }^{3}$ Department of \\ Pathology, Faculty of Medicine, Firat \\ University, Elazig, Turkey; ${ }^{4}$ Department \\ of Periodontology, Faculty of \\ Dentistry, Dicle University, Diyarbakir, \\ Turkey; ${ }^{5}$ Nutrition 2 I, LLC, Purchase, \\ NY, USA; ${ }^{6}$ Department of Animal \\ Nutrition, Faculty of Veterinary \\ Medicine, Firat University, Elazig, \\ Turkey
}

This article was published in the following Dove Press journal:

Drug Design, Development and Therapy

27 June 2016

Number of times this article has been viewed

Background: Arginine silicate inositol complex (ASI; arginine 49.5\%, silicon 8.2\%, and inositol 25\%) is a novel material that is a bioavailable source of silicon and arginine. ASI offers potential benefits for vascular and bone health.

Objective: The aim of this study was to evaluate the potential effects of ASI complex on bone healing of critical-sized defects in rats.

Methods: The rats were randomly assigned to two groups of 21 rats each. The control group was fed a standard diet for 12 weeks; after the first 8 weeks, a calvarial critical-sized defect was created, and the rats were sacrificed 7, 14, and 28 days later. The ASI group was fed a diet containing $1.81 \mathrm{~g} / \mathrm{kg}$ of ASI for 12 weeks; after the first 8 weeks, a calvarial critical-sized defect was created, and the rats were sacrificed 7, 14, and 28 days later. The calvarial bones of all the rats were then harvested for evaluation.

Results: Osteoblasts and osteoclasts were detected at higher levels in the ASI group compared with the control group at days 7,14 , and 28 of the calvarial defect $(P<0.05)$. New bone formation was detected at higher levels in the ASI group compared with the controls at day $28(P<0.05)$. However, new bone formation was not detected at days 7 and 14 in both the groups $(P>0.05)$.

Conclusion: ASI supplementation significantly improved bone tissue healing in rats with critical-sized defects. This study demonstrated that ASI can enhance bone repair and has potential as a therapeutic regimen in humans.

Keywords: arginine silicate inositol, bone healing, osteoblast, osteoclast, critical-sized defect

\section{Introduction}

Loss and defects of jaw bone can stem from trauma, tooth loss, cancer surgery, congenital anomalies, periodontal disease, and oral-maxillofacial pathologies. ${ }^{1,2}$ Regeneration of bone defects is a long healing process, requiring recruitment and differentiation of new bone cells. Various graft materials are used to restore bone defects, but they are prone to failure. Several dietary supplements have been explored for their ability to enhance bone regeneration, such as calcium, vitamin D, and alpha lipoic acid. ${ }^{1,3}$ Recent studies suggest that dietary arginine and silicon may play important roles in the development, growth, and modeling of long bones. ${ }^{4}$ Arginine is involved both in the synthesis of substrates implicated in collagen synthesis and in the production of growth hormone, insulin-like growth factor (IGF)-1, and nitric oxide. ${ }^{5-7}$ Arginine is clinically suggested for metabolic disturbances in calcium absorption, growth, dentition and ossification defects, rachitism, osteomalacia, decalcification, and convalescence. ${ }^{8,9}$ Several roles for silicon have been defined, largely on the basis of animal studies. ${ }^{10,11}$ Its most
Correspondence: Ferhan Yaman Department of Oral-Maxillofacial Surgery, Faculty of Dentistry, Dicle University, Diyarbakir, 21280 , Turkey

Tel +90506I239845

Email dtferhan@hotmail.com 
important functions appear to be involved in the growth and development of bone, cartilage, and connective tissue. There is a direct relationship between silicon and calcium; it has been reported that silicon is associated with calcium at an early stage of bone formation. ${ }^{12,13}$ In addition, silicon appears to be required for the synthesis of collagen, the protein matrix found in connective tissue and cartilage, and which is the single most abundant protein in the human body. ${ }^{12}$

Arginine silicate inositol complex (ASI; arginine 49.5\%, silicon $8.2 \%$, and inositol $25 \%$ ) is a novel, bioavailable source of silicon and arginine and has potential benefits for vascular and bone health. ${ }^{14-17}$ Several studies support the safety of the components of the ASI complex, with clinical studies demonstrating no adverse effects following the administration of arginine. ${ }^{14-19}$ Similarly, no adverse effects were observed following the administration of inositol $12 \mathrm{~g} /$ day for 4 weeks or of silicon $45 \mathrm{mg} /$ day for 31 days. ${ }^{16,20,21}$ The ASI complex is absorbed efficiently, raises plasma arginine levels, and is biologically more effective than the arginine from arginine hydrochloride. ${ }^{14,15}$ The roles of arginine and silicon alone in bone metabolism, osteoporosis, and connective tissue collagen metabolism are well documented, but information about the effects of ASI complex supplementation on bone tissue healing is limited. Therefore, the purpose of this study is to examine the effects of ASI complex supplementation on the healing of calvarial bone tissue defects in rats.

\section{Materials and methods}

A total of 42 female Sprague-Dawley rats were used. Their average body weights were 230-280 g on the first day of the experiment. The animals were kept in temperaturecontrolled cages, exposed to a 12/12-hour light/dark cycle, and had ad libitum access to food and water. The experimental design and study protocol (protocol number: 2015/25) were approved by the animal ethics committee at the University of Dicle. The Helsinki Declaration for laboratory animal care guidelines was strictly obeyed. The rats were randomly divided into two groups of 21 each. The control group was fed a normal diet for 12 weeks; after the first 8 weeks, a calvarial critical-sized defect was created, and the rats were sacrificed 7, 14, and 28 days later. The ASI group was given dietary ASI complex for 12 weeks; after the first 8 weeks, a calvarial critical-sized defect was created, and the rats were sacrificed 7, 14, and 28 days later. A dose of $1.81 \mathrm{~g} / \mathrm{kg}$ was chosen based on a previous rodent study. ${ }^{15}$

To create the calvarial defects, general anesthesia was administered using ketamine, and the surgical operations were performed under sterile conditions, after the skull skin was shaved. A skin incision was made on the skull over the linea media. A periosteal elevator was used to lift the flap and periosteum to reach the skull bone. The skull skin was sutured with 4/0 polyglactin resorbable sutures. Cephalosporin antibiotics and an analgesic were injected intramuscularly into all animals after the operation. After 7, 14, and 28 days, the rats were sacrificed by anesthetic overdose. A surgical drill attached to an electrical hand motor was used to harvest the calvarial bone. The calvarial bone specimens were then separated from muscles and soft tissues. ${ }^{22}$

\section{Histologic and histomorphologic analysis}

The original defect area and the surrounding tissues were used for histological analysis. The specimens were fixed in $10 \%$ formaldehyde for 72 hours and demineralized in 10\% formic acid; after this, they were dehydrated, embedded in paraffin wax, and sectioned for hematoxylin and eosin staining for light microscopy analysis. Sections of $6 \mu \mathrm{m}$ thickness, corresponding to the bone defect area, were evaluated with light microscopy. Osteoblast numbers were scored in the total defect area as follows: 0 , no osteoblast cells; 1 , osteoblasts seen as mild; and 2, osteoblasts seen as dense. Osteoclast cells were detected visually on histomorphometric analysis. Osteoclast cells with ruffled borders were found in both the groups. Osteoclast morphology was scored as follows: 0, no osteoclasts; 1, mild osteoclasts; and 2, dense osteoclasts. To measure bone formation histologically, lamellar bone tissue formation was detected and scored. Trabeculations and bone marrow in lamellar bone tissue, unlike in old bone, were detected. Bone formation was scored as follows: 0 , no bone formation; 1 , mild visible bone formation; 2 , moderate visible bone formation; and 3, dense visible bone formation. Images of all of the histological specimens were captured with a digital camera attached to a light microscope with original magnification and were saved on a computer. The Olympus imaging system (Olympus Bx51, Light Microscope; Olympus DP71, Imaging System; Olympus, Tokyo, Japan) was used for the histomorphometric analysis..$^{22,23}$

\section{Statistical analysis}

For statistical analysis, SPSS software (version 22) was used (IBMCorporation, Armonk, NY, USA). After the healing period, mean values and standard deviations were calculated. According to homogeneity and normality of data, the Wilcoxon test was used for pairwise comparisons in dependent groups. $P$-values of $<0.05$ were considered statistically significant.

\section{Results}

During the postsurgical period, healing was uneventful for both the control and the experimental group animals, and there were 
Table I The effects of ASI on histomorphometric changes

\begin{tabular}{|c|c|c|c|c|}
\hline $\begin{array}{l}\text { Histomorphometic } \\
\text { parameters }\end{array}$ & $\begin{array}{l}\text { Time } \\
\text { (days) }^{\mathrm{a}}\end{array}$ & $\begin{array}{l}\text { Control } \\
(n=2 I)\end{array}$ & $\begin{array}{l}\text { ASI } \\
(n=2 I)\end{array}$ & $P$-value \\
\hline NBF & 7 & 0 & 0 & NA \\
\hline NBF & 14 & 0 & 0 & NA \\
\hline NBF & 28 & $1.14 \pm 0.38$ & $1.57 \pm 0.53 *$ & $<0.001$ \\
\hline$O B$ & 7 & $35.86 \pm 2.55$ & $40.14 \pm 3.02$ & $<0.106$ \\
\hline OB & 14 & $33.86 \pm 2.68$ & $38.14 \pm 2.4 I^{*}$ & $<0.001$ \\
\hline $\mathrm{OB}$ & 28 & $30.29 \pm 1.8$ & $34.58 \pm 2.64 *$ & $<0.001$ \\
\hline OC & 7 & $3.86 \pm 0.69$ & $7.29 \pm 0.76 *$ & $<0.001$ \\
\hline OC & 14 & $2.14 \pm 0.69$ & $4.14 \pm 1.2 I^{*}$ & $<0.001$ \\
\hline$O C$ & 28 & $0.29 \pm 0.49$ & $0.57 \pm 0.53 *$ & $<0.001$ \\
\hline
\end{tabular}

Notes: Data are presented as mean \pm standard deviation. *Significant difference between the without ASI group (control) and the with ASI group (ASI) (t-test). ${ }^{\text {a Days }}$ after the calvarial critical-sized defect was created.

Abbreviations: ASI, arginine silicate inositol complex; NA, not applicable; NBF, new bone formation; $\mathrm{OB}$, osteoblast; $\mathrm{OC}$, osteoclast.

no complications of inflammatory tissue responses or allergic reactions. As seen in Table 1 and Figures 1-3, at days 7 and 14 , new bone formation was not detected in either group and at day 28 , new bone formation in both the groups was increased compared with that at days 7 and $14(P<0.05)$. Overall, the mean new bone area in the control group was lower compared with that in the ASI group at day $28(P<0.05)$.

At days 7, 14, and 28, osteoclast numbers were higher in the ASI group compared with those in the control group
$(P<0.05)$. At day 7 , no statistically significant difference in osteoblast numbers was detected between the two groups $(P>0.05)$. At days 14 and 28, osteoblast numbers were higher in the ASI group compared to the controls $(P<0.05)$ (Table 1; Figures 1-3).

The ASI complex used in the present study does not cause adverse effects when administered orally for up to 8 weeks in rats; and it lacks mutagenic potential, as demonstrated in two separate genotoxicity studies. ${ }^{16,17}$ Rat calvarial defects are considered a preferred experimental model for bone regeneration. For this reason, a $5-\mathrm{mm}$ rat calvarial critical-sized defect model was used, in accordance with previous studies. . $223^{23}$

In the literature, research is limited with regard to the ASI complex in osteoblastic metabolism, connective tissue and vessel collagen metabolism, and osteoporosis. However, the positive immunological activities of arginine and silicon are well known, and the osteoblastic activity and woundhealing processes in bone and connective tissues are well documented. ${ }^{14-17}$ Based on the present study, ASI complex supplementation may be an effective material for the treatment of bone tissue defects.

Two components of the product used in the present study, arginine and silicon, can increase osteogenesis. ${ }^{8,12,24}$
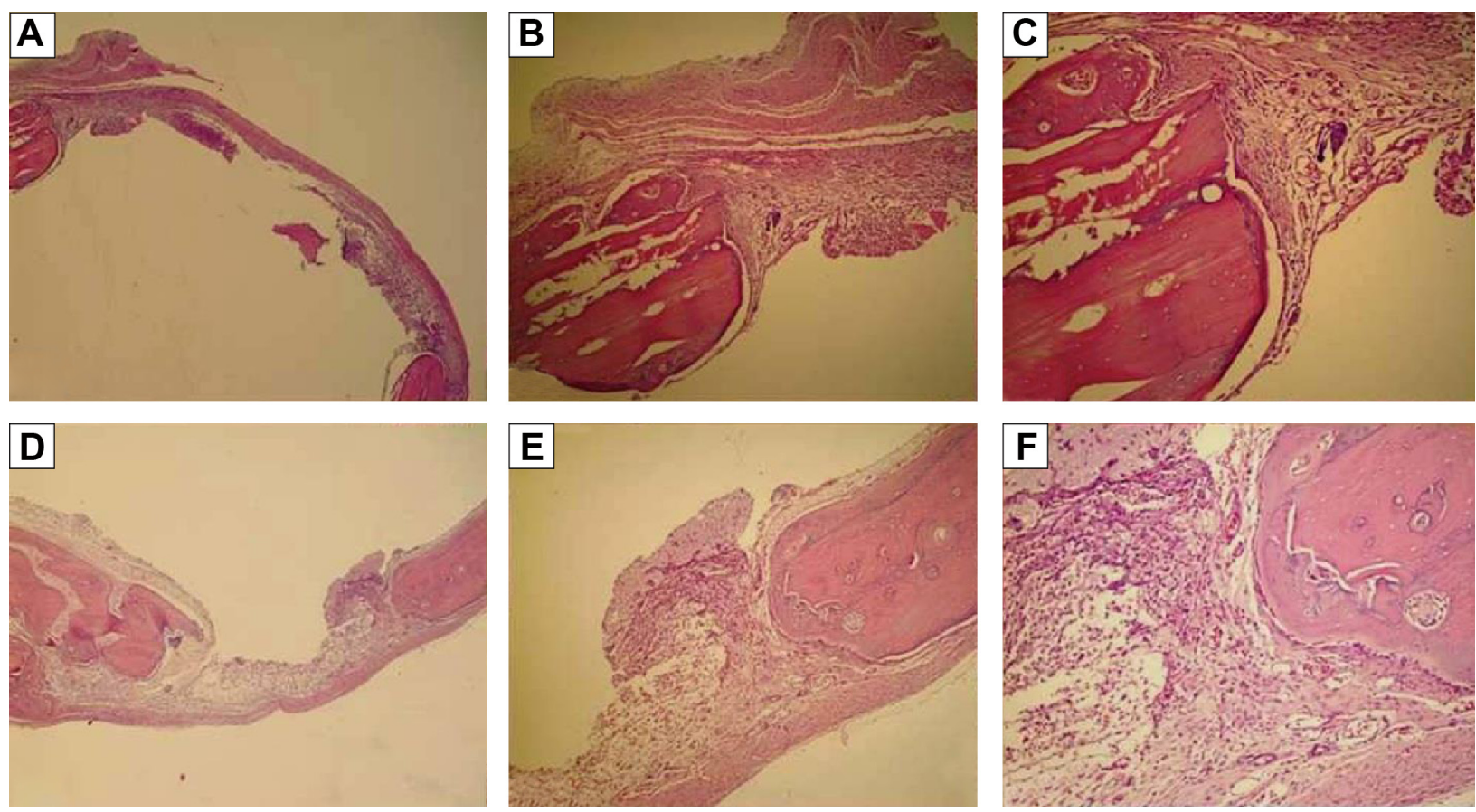

Figure I Histopathologic sections of both the groups at 7 days.

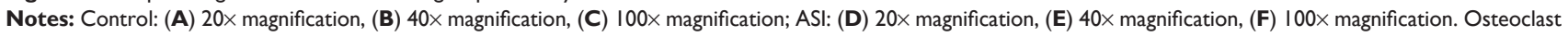
morphology was scored as follows: 0 , no osteoclasts; I, mild osteoclasts; and 2, dense osteoclasts. Bone formation was scored as follows: 0 , no bone formation; I, mild visible bone formation; 2, moderate visible bone formation; and 3, dense visible bone formation.

Abbreviation: ASI, arginine silicate inositol complex. 

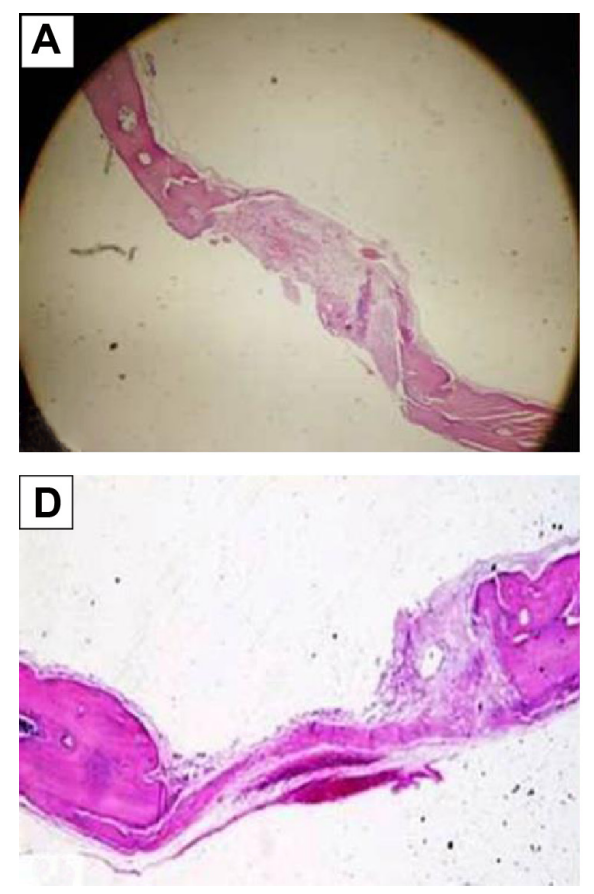
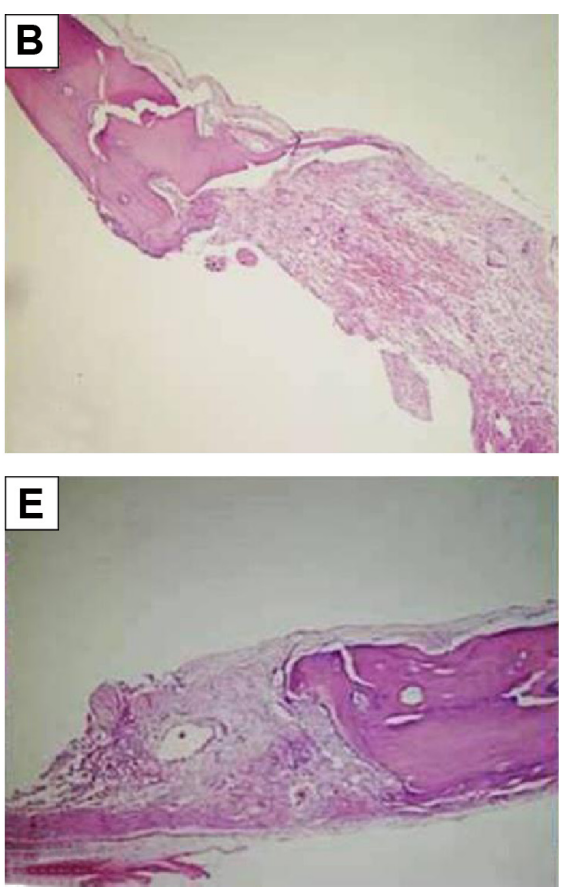
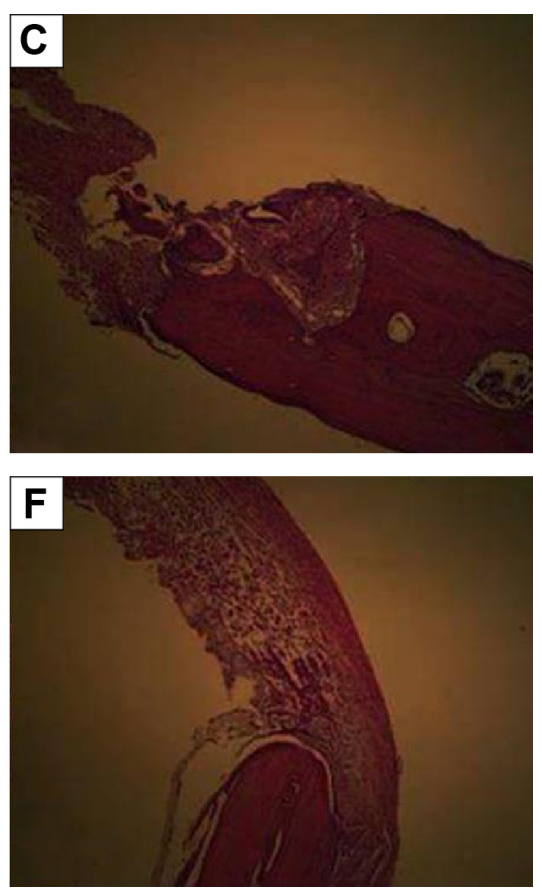

Figure 2 Histopathologic sections of both the groups at 14 days.

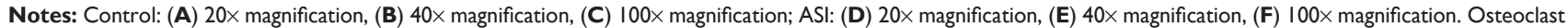
morphology was scored as follows: 0 , no osteoclasts; I, mild osteoclasts; and 2 , dense osteoclasts. Bone formation was scored as follows: 0 , no bone formation; I, mild visible bone formation; 2, moderate visible bone formation; and 3, dense visible bone formation.

Abbreviation: ASI, arginine silicate inositol complex.
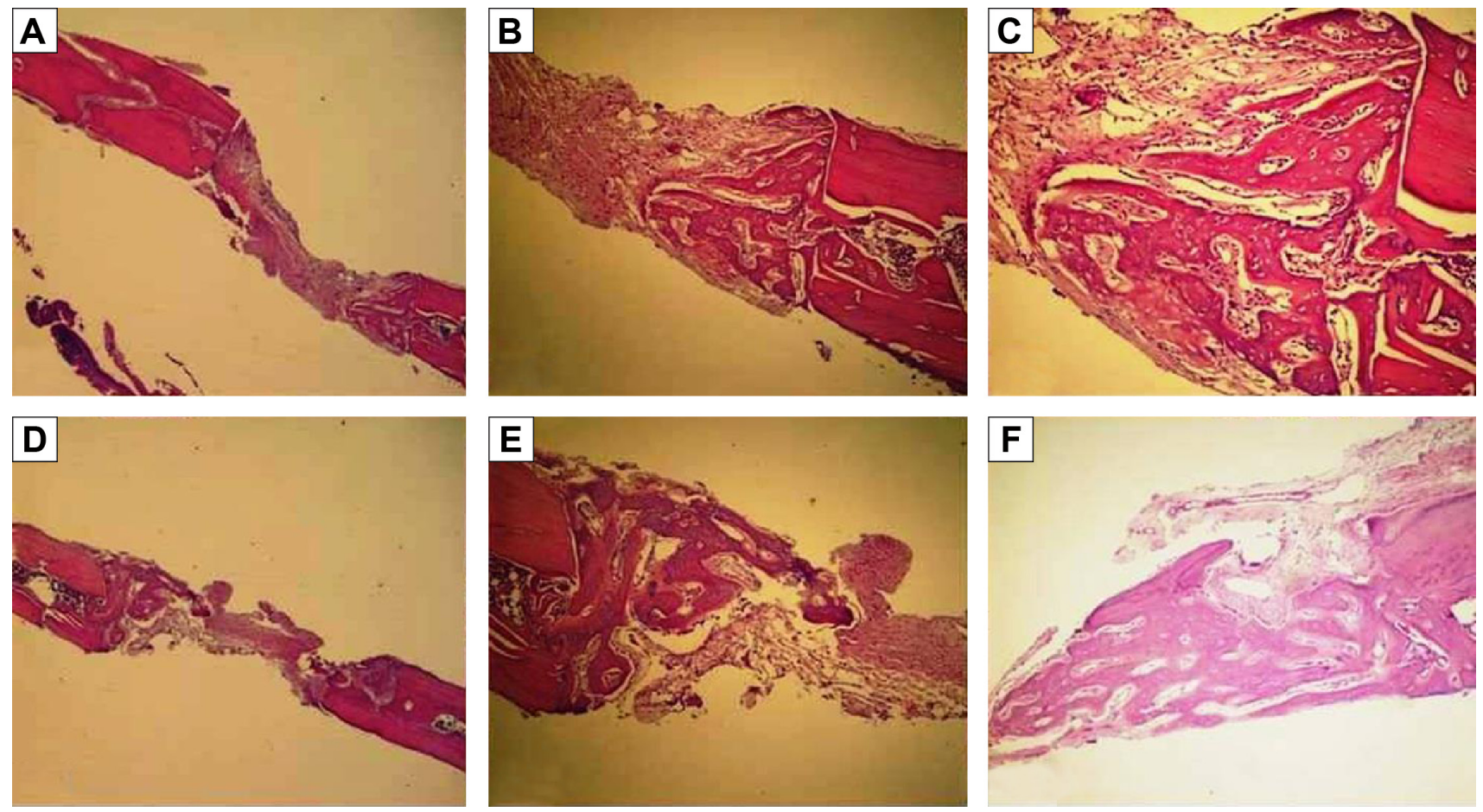

Figure 3 Histopathologic sections of both the groups at 28 days.

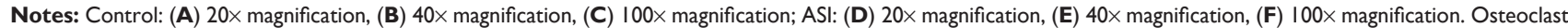
morphology was scored as follows: 0 , no osteoclasts; I, mild osteoclasts; and 2, dense osteoclasts. Bone formation was scored as follows: 0 , no bone formation; I, mild visible bone formation; 2, moderate visible bone formation; and 3, dense visible bone formation.

Abbreviation: ASI, arginine silicate inositol complex. 
Arginine deficiency may be involved in osteoporosis, fractures, and bone defects ${ }^{25}$ and arginine may be involved in the synthesis of polyamine and L-proline (which act as substrates for collagen synthesis) and of growth hormone and IGF, and in nitric oxide production. ${ }^{5-7}$ Nitric oxide has been shown to prevent corticosteroid-induced bone loss in mature rats. ${ }^{26}$ Torricelli et $\mathrm{al}^{27}$ reported that arginine in human osteoblasts markedly increased certain parameters called bone-formation markers, such as alkaline phosphatase, nitric oxide, type I collagen, and IGF. These markers increase the synthesis of bone matrix, acting at the cellular level in bone tissue. Torricelli et $\mathrm{al}^{27}$ also reported that the effects of arginine on bone tissue were directly related to the effect on the cell proliferation mechanism. In the same study, IL-6 production was determined to be lower in osteoblasts exposed to arginine. ${ }^{27}$

Silicon has been implicated as an important component in bone formation, and its deficiency negatively influences skeletal development. ${ }^{11}$ The primary effect of silicon in bone and cartilage is thought to be on matrix synthesis, although it also has a significant influence on calcification. ${ }^{28}$ Silicon supplementation inhibits bone resorption and increases trabecular bone volume and bone mineral density in postmenopausal women with osteoporosis. ${ }^{25}$ Although limited research has been done in vivo, silicon increases osteoblastic activity and decreases osteoclastic activity in vitro. ${ }^{16,17,29}$ Schroder et al $^{30}$ and Wiens et $\mathrm{al}^{31}$ reported that osteoprotegerin produced increased osteoblast-like cells exposed to silicate; but no changes occurred in the production of the receptor activator of NF- $\mathrm{kB}$ ligand. These researchers stated that the increased osteoprotegerin emission suppressed the receptor activator of NF- $\kappa \mathrm{B}$ ligand activity, and consequently increased osteoclastogenesis. Additionally, Sahin et $\mathrm{al}^{16}$ and Önderci et $\mathrm{al}^{17}$ examined the effects of ASI on bone tissue in a study on poultry fed a diet supplemented with $500 \mathrm{mg} / \mathrm{kg}$ and 1,000 mg/kg, respectively. In these studies, an increase in the levels of bone mineral density, calcium, and phosphorus in the tibia and of osteocalcin and alkaline phosphatase in the serum, depending on the dose in both the experimental groups compared to the controls, was determined. The findings of the present study confirmed these previous results. In this study, bone formation and bone metabolism associated with bone remodeling and the bone tissue healing process were statistically significantly higher (eg, osteoblast and osteoclast numbers and area of new bone formation) in the ASI-supplemented group compared to the controls. During the bone tissue healing and remodeling process, osteoblasts and osteoclasts act together. These findings also indicate significant positive associations between ASI intake and bone metabolism in the bone tissue defect model used in this experiment.

This study had some limitations. Only the calvarium of the animals were used; however, other skeletal animal parts, for example, long bones (tibia and femur), would be useful for an analysis of the long-bone tissue effects of ASI supplementation. In addition, the histomorphometric method was used for the analysis of the bone tissue effects of ASI, but micro-computerized tomography would be very useful for a better analysis of ASI supplementation in calvarial bones. In addition, the potent anti-inflammatory effects of arginine are well known; however, no research about these effects was made.

\section{Conclusion}

Within the limitations of this study, ASI complex could increase bone tissue healing in the rat calvarial critical-sized defect model. Further studies are needed on the effects of ASI complex on bone tissue healing mechanisms and on the effects of new materials on these mechanisms.

\section{Acknowledgments}

The authors thank Nutrition 21 Inc (NY, USA) for providing ASI complex. This work was supported in part by the Turkish Academy of Sciences (KS).

\section{Disclosure}

The authors report no conflicts of interest in this work. The authors alone are responsible for the content and writing of the paper.

\section{References}

1. Acar AH, Yolcu Ü, Altindiş S, Gül M, Alan H, Malkoç S. Bone regeneration by low-level laser therapy and low-intensity pulsed ultrasound therapy in the rabbit calvarium. Arch Oral Biol. 2016;61:60-65.

2. Akman S, Canakci V, Kara A, Tozoglu U, Arabaci T, Dagsuyu IM. Therapeutic effects of alpha lipoic acid and vitamin $\mathrm{C}$ on alveolar bone resorption after experimental periodontitis in rats: a biochemical, histochemical, and stereologic study. J Periodontol. 2013;84(5):666-674.

3. Reid IR, Bristow SM, Bolland MJ. Calcium supplements: benefits and risks. J Intern Med. 2015;278(4):354-368.

4. Seaborn CD, Nielsen FH. Silicon deprivation decreases collagen formation in wounds and bone, and ornithine transaminase enzyme activity in liver. Biol Trace Elem Res. 2002;89(3):251-261.

5. Chevalley T, Rizzoli R, Manen D, Caverzasio J, Bonjour JP. Arginine increases insulin-like growth factor-I production and collagen synthesis in osteoblast-like cells. Bone. 1998;23(2):103-109.

6. Trippel SB. Potential role of insulin-like growth factors in fracture healing. Clin Orthop Relat Res. 1998;(355 Suppl):301-313.

7. Colao A, Di Somma C, Pivonello R, et al. Bone loss is correlated to the severity of growth hormone deficiency in adult patients with hypopituitarism. J Clin Endocrinol Metab. 1999;84(6):1919-1924.

8. Fiore CE, Pennisi P, Cutuli VM, Prato A, Messina R, Clementi G L-arginine prevents bone loss and bone collagen breakdown in cyclosporin A-treated rats. Eur J Pharmacol. 2000;408(3):323-326. 
9. Clementi G, Fiore CE, Mangano NG, et al. Role of soy diet and L-arginine in cyclosporin-A-induced osteopenia in rats. Pharmacol Toxicol. 2001;88(1):16-19.

10. Carlisle EM. Silicon: an essential element for the chick. Science. 1972; 178(4061):619-621.

11. Schwarz K, Milne DB. Growth-promoting effects of silicon in rats. Nature. 1972;239(5371):333-334.

12. Carlisle EM. In vivo requirement for silicon in articular cartilage and connective tissue formation in the chick. J Nutr. 1976;106(4):478-484.

13. Carlisle EM. Silicon: a requirement in bone formation independent of vitamin D1. Calcif Tissue Int. 1981;33(1):27-34.

14. Proctor SD, Kelly SE, Russell JC. A novel complex of arginine-silicate improves micro- and macrovascular function and inhibits glomerular sclerosis in insulin-resistant JCR:LA-cp rats. Diabetologia. 2005;48(9): 1925-1932.

15. Proctor SD, Kelly SE, Vine DF, Russell JC. Metabolic effects of a novel silicate inositol complex of the nitric oxide precursor arginine in the obese insulin-resistant JCR:LA-cp rat. Metabolism. 2007;56(10): 1318-1325.

16. Sahin K, Onderci M, Sahin N, et al. Dietary arginine silicate inositol complex improves bone mineralization in quail. Poult Sci. 2006;85(3): 486-492.

17. Onderci M, Sahin N, Sahin K, et al. Dietary arginine silicate inositol complex during the late laying period of quail at different environmental temperatures. Br Poult Sci. 2006;47(2):209-215.

18. Adams MR, Forsyth CJ, Jessup W, Robinson J, Celermajer DS. Oral L-arginine inhibits platelet aggregation but does not enhance endothelium-dependent dilation in healthy young men. J Am Coll Cardiol. 1995;26(4):1054-1061.

19. Lerman A, Burnett JC Jr, Higano ST, McKinley LJ, Holmes DR Jr. Long-term L-arginine supplementation improves small-vessel coronary endothelial function in humans. Circulation. 1998;97(21): 2123-2128.

20. Levine J. Controlled trials of inositol in psychiatry. Eur Neuropsychopharmacol. 1997;7(2):147-155.
21. Van Dyck K, Robberecht H, Van Cauwenbergh R, Van Vlaslaer V, Deelstra H. Indication of silicon essentiality in humans: serum concentrations in Belgian children and adults, including pregnant women. Biol Trace Elem Res. 2000;77(1):25-32.

22. Toker H, Ozdemir H, Ozer H, Eren K. A comparative evaluation of the systemic and local alendronate treatment in synthetic bone graft: a histologic and histomorphometric study in a rat calvarial defect model. Oral Surg Oral Med Oral Pathol Oral Radiol. 2012;114(5 Suppl): 146-152.

23. Toker H, Ozdemir H, Ozer H, Eren K. Alendronate enhances osseous healing in a rat calvarial defect model. Arch Oral Biol. 2012;57(11): 1545-1550.

24. Carlisle EM. Silicon: a possible factor in bone calcification. Science. 1970;167(3916):279-280.

25. Eisinger J, Clairet D. Effects of silicon, fluoride, etidronate and magnesium on bone mineral density: a retrospective study. Magnes Res. 1993; 6(3):247-249

26. Wimalawansa SJ, Chapa MT, Yallampalli C, Zhang R, Simmons DJ. Prevention of corticosteroid-induced bone loss with nitric oxide donor nitroglycerin in male rats. Bone. 1997;21(3):275-280.

27. Torricelli P, Fini M, Giavaresi G, et al. L-arginine and L-lysine stimulation on cultured human osteoblasts. Biomed Pharmacother. 2002; 56(10):492-497.

28. Seaborn CD, Nielsen FH. Effects of germanium and silicon on bone mineralization. Biol Trace Elem Res. 1994;42(2):151-164.

29. Schütze N, Oursler MJ, Nolan J, Riggs BL, Spelsberg TC. Zeolite A inhibits osteoclast-mediated bone resorption in vitro. $J$ Cell Biochem. 1995;58(1):39-46.

30. Schröder HC, Wang XH, Wiens M, et al. Silicate modulates the crosstalk between osteoblasts ( $\mathrm{SaOS}-2$ ) and osteoclasts (RAW 264.7 cells): inhibition of osteoclast growth and differentiation. $J$ Cell Biochem. 2012;113(10):3197-3206

31. Wiens $\mathrm{M}$, Wang $\mathrm{X}$, Schröder $\mathrm{HC}$, et al. The role of biosilica in the osteoprotegerin/RANKL ratio in human osteoblast-like cells. Biomaterials. 2010;31(30):7716-7725.
Drug Design, Development and Therapy

\section{Publish your work in this journal}

Drug Design, Development and Therapy is an international, peerreviewed open-access journal that spans the spectrum of drug design and development through to clinical applications. Clinical outcomes, patient safety, and programs for the development and effective, safe, and sustained use of medicines are a feature of the journal, which
Dovepress

has also been accepted for indexing on PubMed Central. The manuscript management system is completely online and includes a very quick and fair peer-review system, which is all easy to use. Visit http://www.dovepress.com/testimonials.php to read real quotes from published authors. 